\title{
EDUCAÇÃO PÚBLICA: FALTA DE PRIORIDADE DO PODER PÚBLICO OU DESINTERESSE DA SOCIEDADE?+
}

\author{
PUBLIC EDUCATION: NOT A PRIORITY OF THE PUBLIC POWER OR \\ DISINTEREST OF SOCIETY?
}

\author{
Elias P Marques" \\ Maria C F Pelicioni** \\ Isabel M T B Pereira***
}

\begin{abstract}
Marques EP, Pelicioni MCF, Pereira IMTB.Educação Pública: falta de prioridade do poder público ou desinteresse da sociedade?. Rev Bras Crescimento Desenvol Hum. 2007; 17(3):08-20.
\end{abstract}

\begin{abstract}
Resumo: A sociedade brasileira não dispõe de uma educação pública de qualidade por não ser esta uma prioridade do poder público, por outro lado o poder público não a prioriza por não ser uma demanda da sociedade. Acredita-se que para legitimar qualquer diálogo e iniciativa no campo da educação precisa-se envolver os seus legítimos protagonistas, os professores. Realizou-se, desta forma, uma pesquisa+ qualitativa com professores de uma escola municipal de ensino fundamental da cidade de São Paulo, buscando identificar, por meio de entrevistas semiestruturadas, as suas representações sociais sobre o atual papel da escola pública e as iniciativas do poder público que buscam integrar áreas como a saúde e o meio ambiente no espaço escolar. No eixo de investigação aqui discutido, "o poder público e a escola pública", constatou-se que o assistencialismo, a ineficiência de políticas públicas e o desconhecimento da escola pelos gestores públicos são evidências do descaso do Estado para o desenvolvimento de uma escola de qualidade, sendo esses alguns dos determinantes do descumprimento do papel da instituição escola. O professor tem se sentido cada vez mais impotente, desvalorizado e desinteressado pela educação pública. Assim, cabe à sociedade assumir sua responsabilidade diante do ensino público e ao poder público cabe não só compreender, mas, principalmente vivenciar a escola estabelecendo um diálogo verdadeiro e profundo com o professor, buscando, por meio da educação, uma transformação social sustentável baseada em valores humanos mais éticos e mais justos.
\end{abstract}

Palavras-chave: Ensino fundamental. Educação de qualidade. Promoção da saúde. Professor. Poder público. Pesquisa qualitativa.

\section{Panorama Sócio-Político da Educação Pública de Ensino Básico}

A sociedade brasileira vem terceirizando, histórico-culturalmente, seus eventuais fracassos e suas responsabilidades, atribuindo-os ao Estado, ao sistema político-econômico, ao diretor e ao professor da escola, ao síndico do prédio ou ao destino, isentando-se da obrigação de pensar e agir, da urgência em mudar seus hábitos e valores e de transformar a si e ao seu mundo, negando-se a assumir definitivamente seu papel diante das necessidades contemporâneas, em especial no que diz respeito ao ensino público de educação básica - educação infantil, ensino fundamental e ensino médio. Para Squizato ${ }^{1}$ (2006),

Mestre em Saúde Pública pela Faculdade de Saúde Pública da USP e Especialista em Educação Ambiental. Email: eliaspmarques@usp.br

** $\quad$ Prof $^{a}$ Associada e Doutora da Faculdade de Saúde Pública da USP

*** Prof ${ }^{\text {a }}$ Doutora da Faculdade de Saúde Pública da USP

+ O presente artigo faz parte da dissertação "Educação, Saúde, Meio Ambiente e Políticas Públicas: o que pensam os professores?”, desenvolvida na Faculdade de Saúde Pública da USP por Elias P. Marques sob orientação da Prof ${ }^{a}$ Dr ${ }^{\mathrm{a}}$ Isabel M.T.B. Bicudo. 
a falta de indignação da sociedade diante da baixa qualidade da escola pública também faz parte do problema educacional no Brasil.

Por outro lado, e seguindo as principais estratégias neoliberais, verifica-se a transferência, cada vez maior, da responsabilidade e dos deveres legais do poder público à sociedade, o que resulta em uma perigosa privatização do papel do Estado, encontrando nas escolas públicas um território favorável e subserviente à consolidação dessa prática. Freire ${ }^{2}$ (1996, p. 19) posiciona-se permanentemente crítico à malvadez neoliberal, à sua cínica ideologia fatalista e imobilizante, à sua recusa inflexível ao sonho e à insistência no convencimento de que nada se pode fazer "contra a realidade social que, de histórica e cultural, passa a ser ou a virar "quase natural'."

Com isso, a sociedade civil vem aos poucos ocupando espaços tradicionalmente vinculados ao Estado, como é o caso do programa Amigos da Escola, que busca na valorização do voluntariado a adesão da população para suprir as deficiências do poder público e encontra campo fértil na rede pública de ensino fundamental, atualmente com 30 milhões de alunos matriculados" e 1,4 milhões de funções docentes em aproximadamente 140 mil escolas, segundo o Censo Escolar de 2006 realizado pelo Instituto Nacional de Estudos e Pesquisas Educacionais Anísio Teixeira (INEP $\left.{ }^{3}, 2007\right)$.

Nesse contexto têm surgido, mesmo que ainda em fase embrionária, importantes iniciativas rumo à construção de um movimento nacional em prol de uma educação pública de qualidade no ensino básico, embora até o momento não se tenha definido, pelo menos de forma clara e consensual, o que seria e como se alcançaria essa "qualidade".

Assim, o setor privado - cada vez mais exigente em relação à qualificação da mão-deobra e recentemente demandando também características como criatividade e bom relacionamento interpessoal - demonstra preocupação com os resultados que estão sendo obtidos na educação pública e se organiza para cooperar e reivindicar mudanças, como é o caso do Movimento Todos pela Educação, idealizado por grandes corporações.

No terceiro setor, há iniciativas que buscam desde o desenvolvimento de ações em áreas específicas, como esporte, arte, meio ambiente e saúde, até as de mobilização da sociedade pela reivindicação de políticas públicas eficientes e participativas, como é o caso da organização Ação Educativa e da Campanha Nacional pelo Direito à Educação.

Na Academia têm-se notado, nos últimos tempos, uma maior abertura e disposição na aproximação entre a práxis educativa e os seus atores, no intuito de estabelecer um diálogo interdisciplinar, situacional, e de perspectivas, que intensifique a promoção de eventos divulgadores de novos conceitos, pesquisas e casos da prática escolar, proporcionando a sensibilização e atualização dos educadores escolares.

No caso dos gestores públicos, infelizmente, a educação de qualidade ainda parece longe de fazer parte de suas prioridades, ficando à mercê de um sem-número de problemas, tais como a tradicional descontinuidade das iniciativas educacionais, a superlotação das salas de aula, a deficiência na formação do professor, o descaso com a saúde do aluno e a do professor, entre outros; além da polêmica relacionada ao financiamento da educação básica pública. Segundo Cunha, atual secretário de Educação da Organização das Nações Unidas para a Educação, a Ciência e a Cultura (Unesco) no Brasil, para recuperar o atraso do sistema educacional brasileiro seria necessário dobrar o investimento, o que resultaria em uma alteração positiva no indicador de gasto anual por criança em educação (Squizato ${ }^{1}, 2006$ ), que de acordo com a Organização para a Cooperação e o Desenvolvimento Econômico $\left(\mathrm{OECD}^{4}, 2006\right)$, é de US\$1.009, inferior a outros países latino-americanos.

$\mathrm{Na}$ última eleição presidencial brasileira, como um indício do despertar em direção à construção do movimento pela educação pública de

\# Sendo que cerca de $70 \%$ das matrículas no ensino público fundamental brasileiro encontra-se sob dependência administrativa municipal. 
qualidade - embora esse seja um sinal ainda mais simbólico do que prático -, um dos candidatos pautou a Educação como o principal pilar de seu programa de governo, propondo, por meio desta, uma revolução no País. Isso desencadeou um efeito cascata: todos os outros candidatos passaram a inserir a questão educacional em seus discursos.

Assim, a histórica falta de prioridade com o ensino público básico e a sua ausência nos planos diretores e propostas do Estado, até por não fazer parte das prioridades da própria sociedade, está refletida, por consequiência, em prejuízos na concepção e implementação de políticas públicas eficientes que tragam verdadeiramente resultados substanciais à melhoria da qualidade da escola pública de ensino básico.

Tem-se, então, o seguinte dilema: a sociedade não tem uma educação pública básica de qualidade porque esta não é prioridade do poder público. Por outro lado, o poder público não a prioriza porque isso não constitui uma demanda da sociedade e, portanto, não desperta o interesse político. Em concordância e buscando o despertar da sociedade, Cunha ${ }^{5}$ (2006) considera que hoje a educação não é uma prioridade para a sociedade brasileira. É preciso que o Estado evidencie a importância da educação de qualidade como estratégia de combate às problemáticas sociais.

Dessa forma, a educação pública tornase determinante na qualidade que se obtém ou se deseja obter em outros campos da sociedade, tais como o social - no combate à pobreza, à injustiça e à desigualdade; o cultural - na formação de novos hábitos e valores; o político - na construção da cidadania ativa e crítica; e o ambiental - na sustentabilidade do planeta e de todas as formas de vida.

Faz-se então necessária uma grande reestruturação qualitativa da educação pública brasileira de ensino básico, considerando os inúmeros desafios e envolvendo de forma participativa e cooperativa todos os atores da sociedade. Acredita-se ainda que, para legitimar qualquer diálogo e iniciativa no campo da educação, é preciso o envolvimento verdadeiro dos autênticos protagonistas da práxis educativa - os professores -, partindo dos seus sonhos, angústias, sugestões e experiências, acumulados ao longo dos anos de magistério, além das passagens por escolas diversas e as inúmeras mudanças de gestores públicos. De acordo com Paro $^{6}$ (2001, p. 123), "sem a confiança e o empenho dos que fazem o ensino, não é razoável esperar qualquer êxito das soluções e propostas que são apresentadas pelos que elaboram e estudam as políticas educacionais."

\section{Poder Público e Ensino Público Fundamen- tal: o que pensam os professores?}

Acreditando na extrema necessidade de dar voz ao educador para obter perspectivas reais da atual situação da escola pública, buscou-se, nesta pesquisa, ouvir professores da rede pública de ensino fundamental da cidade de São Paulo, identificando suas concepções, angústias, valores, sonhos e opiniões acerca do papel da escola pública diante das complexas demandas da sociedade e das iniciativas intersetoriais e interdisciplinares do poder público que visam integrar áreas como a saúde e o meio ambiente no espaço escolar. Acredita-se, desta forma, na efetiva contribuição à reflexão da coletividade dos que fazem e pensam a educação, assim como, ao desenvolvimento de políticas públicas educacionais mais eficientes e participativas, assumindo a academia a sua parcela de responsabilidade no atual fracasso da educação pública básica.

Recorreu-se, então, à metodologia qualitativa de investigação, que segundo Minayo ${ }^{7}$ (1994), aprofunda o universo de significados, aspirações, crenças, valores e atitudes, o que corresponde ao espaço mais íntimo das ações e relações humanas, tendo em seus alicerces, de acordo com Lefèvre ${ }^{8}$ et al. (2000), o princípio de que o pensamento de uma coletividade é o conjunto de representações geradas nas práticas discursivas, presentes em uma dada formação social e em um dado momento histórico.

Desse modo, considerou-se que o olhar sobre essa representação social seria o caminho ideal para a identificação desses sentimentos e valores dos professores, levando em conta a teia de significados sociais observados em suas falas 
e práticas cotidianas. Para Moscovici ${ }^{9}$ (1978), representação social é o senso comum de um grupo sobre um determinado tema, manifestado na construção coletiva de preconceitos, ideologias e características específicas das atividades sociais e profissionais.

Considerando que a maior parte dos professores acumula vários anos de magistério, passagem por inúmeras escolas da rede pública municipal, estadual e particular e um sem-número de mudanças nas políticas educacionais, ocorridas conforme a alternância de gestores públicos e seus respectivos partidos políticos, optouse por trabalhar com uma única escola ${ }^{\# \#}$.

Essas premissas foram confirmadas na caracterização ${ }^{\# \#}$ e nos depoimentos dos docentes participantes. Michelat ${ }^{10}$ (1987) reafirma que a relevância em uma pesquisa qualitativa, como é o caso deste estudo, não é a representatividade estatística dos fenômenos, por isso mesmo poucas pessoas são investigadas. Assim, o indivíduo é considerando representativo por deter uma imagem particular da cultura à qual pertence.

Para a coleta de dados junto aos professores dessa escola, utilizou-se entrevistas semi-estruturadas, que foram realizadas entre junho e outubro de 2006 com 29 docentes. Na interpretação dos depoimentos e identificação das representações sociais desses atores utilizou-se a análise de conteúdo temática, que de acordo com $\operatorname{Bardin}^{11}$ (1979), consiste em descobrir os núcleos de sentido do discurso e cuja identificação pode contribuir para a análise do objeto de pesquisa. Para tal utilizou-se o método Discurso do Sujeito Coletivo, que segundo Lefèvre e Lefèvre ${ }^{12}$ (2005, p. 15-6) consiste em reunir em um único discurso as várias narrativas individuais que se assemelham ou se complementam, de modo que o resultado fique o mais próximo do pensamento da coletividade, "uma proposta de organização e tabulação de dados qualitativos de natureza verbal obtidos de depoimentos." (p. 15-6).

Esta pesquisa guiou-se por cinco eixos centrais de investigação: Papel da instituição Escola; Dificuldades e facilidades no ensino público fundamental; Situação do professor no ensino público fundamental; Saúde e meio ambiente no ensino público fundamental; Poder público e ensino público fundamental, sendo que este permeia todos os anteriores.

Neste artigo serão apresentados os resultados referentes ao eixo "Poder público e ensino público fundamental", que busca compreender, na visão do professor, o papel da instituição escola e o cumprimento ou não deste pela escola pública, desvelando as principais dificuldades relacionadas ao poder público e a situação do docente diante desse cenário e de novas demandas, em particular na área da saúde e do meio ambiente.

\section{A relação entre o poder público e o papel da instituição Escola}

Por meio da pergunta "Na sua opinião, qual é o verdadeiro papel da instituição Escola?", verificou-se que os professores entendiam a escola como um lócus responsável, essencialmente, por: transmitir conhecimentos; preparar o aluno para o mercado de trabalho; formar valores humanos positivos; educar para a cidadania; despertar as potencialidades do aluno; ser um espaço assistencialista; e ser um espaço socializador.

Após serem identificadas essas representações, partiu-se para a investigação das concepções sobre o cumprimento ou não desse papel pela escola fundamental pública. Para tal, utilizou-se a questão "Você acha que a escola pública está conseguindo cumprir esse papel? Fale um pouco sobre isso."

Relacionado ao poder público, constatou-

\#\# Estabeleceu-se parceria com uma Escola Municipal de Ensino Fundamental (Emef), localizada no Jardim São Luiz, zona sul do município de São Paulo, região com quadros sócio-econômico, educacional e ambiental altamente precários e de exclusão.

\#\# Caracterizado por $76 \%$ de mulheres, $65,5 \%$ com idade entre 31 e 50 anos, $76 \%$ exerciam o magistério há mais de 10 anos, $66 \%$ cumpriam Jornada Especial Integral (JEI), 63\% eram titulares da escola e $72 \%$ lecionavam, também, em outras escolas. 
se que, para alguns docentes, a escola pública procurava cumprir a sua função da melhor maneira possível, esforçando-se para superar dificuldades de infra-estrutura física e humana, lidando com a freqüente descontinuidade das políticas públicas educacionais, e buscando adequar-se às novas demandas da sociedade; desta forma seus objetivos eram parcialmente alcançados, conforme revelado no seguinte discurso: "em muitas coisas a gente até que consegue, mas é muita coisa para a escola resolver, fica tudo um pouquinho. Não transfiram todos os problemas sociais para nós! Não ponham tudo nas nossas mãos porque a gente não vai dar conta!"

$\mathrm{Na}$ opinião de outros docentes, devido à ausência de políticas públicas e à falta de apoio estrutural e pedagógico por parte dos gestores públicos, para que a escola pública cumprisse o seu papel, ainda que parcialmente, era necessária a participação ativa da comunidade local e, principalmente, a boa vontade dos seus educadores. Existia aqui, porém, uma perigosa armadilha: por ser o docente da rede pública de ensino pouco cobrado sobre o seu trabalho, a qualidade de sua atuação pedagógica estava diretamente associada à sua consciência de educador, conforme ilustrado no seguinte discurso: "então, tem que contar com muita boa vontade dos professores, da direção, da orientação, porque não tem uma coisa por trás [poder público], ajudando mesmo na parte educacional. Na escola particular você é mais cobrado e aqui quem te cobra é a sua consciência."

Mas, para a maioria desses professores, a escola pública de ensino fundamental descumpria o seu papel, sendo que uma das principais idéias associadas relacionava-se ao assistencialismo institucionalizado pelo poder público, fator particularmente significativo na rede pública municipal de São Paulo. Assim, esses docentes acreditavam que os gestores públicos desviavam, estrategicamente, a função educacional da escola, usando-a como um espaço de auto-promoção, conforme evidenciado no seguinte discurso: "a escola está assumindo funções que não são dela. Eles [poder público] estão desvirtuando o papel da educação, estão fazendo é politicagem."

Para esses educadores, o assistencialismo não deveria fazer parte das funções da escola e essas práticas não deveriam interferir no calendário escolar. Acreditavam, ainda, que a função da escola pública estava perdida, visto que não se cumpria nem mesmo a educação formal, já que essa instituição assumia, gradativamente, as responsabilidades que cabiam à família e à sociedade, sobrecarregando-se de funções que, definitivamente, não eram suas.

Outra concepção revelada nas entrevistas, relacionada ao poder público, referia-se ao pensamento de que a escola pública descumpria o seu papel porque os gestores públicos não conheciam a realidade, especificidades e necessidades dessa instituição, sendo esse um dos principais motivos dos contínuos fracassos das iniciativas, projetos e programas educacionais.

Para minimizar esse cenário histórico, fazse necessário que não só o poder público, mas também aqueles que pensam e pesquisam a educação, aproximem-se dos educadores escolares, em especial do professor, buscando compreender os aspectos sociais, políticos, culturais, ambientais e pedagógicos envolvidos na práxis educativa. Sobre essa questão, $\operatorname{Paro}^{6}$ (2001, p. 123) vai além, ao afirmar que "sem a confiança e o empenho dos que fazem o ensino, não é razoável esperar qualquer êxito das soluções e propostas que são apresentadas pelos que elaboram e estudam as políticas educacionais."

Outra idéia associada ao descumprimento da função da escola pública era a falta ou ineficiência das políticas públicas, sendo que essa instituição via-se obrigada a lidar com a descontinuidade das iniciativas educacionais devido, principalmente, ao desinteresse do Estado com a escola básica pública.

Para outros docentes, os métodos pedagógicos eram inadequados e, portanto, não estimulavam o aprendizado do aluno, conforme observado no seguinte discurso: "não cumpre, pois é um tipo de aprendizado um pouco arcaico no sentido de que eu já tenho o que é para ser passado, então eu acho que a gente não tem cumprido muito bem esse papel não." De acordo com Freire ${ }^{2}$ (1996, p. 33), "transformar a 
experiência educativa em puro treinamento técnico é amesquinhar o que há de fundamentalmente humano no exercício educativo: o seu caráter formador."

Identificou-se, nas narrativas dos professores, a idéia de que a carga horária da escola pública era insuficiente, principalmente em boa parte das escolas da rede municipal de São Paulo, que trabalhavam com o turno intermediário ( $3^{\circ}$ turno diurno). Góis ${ }^{13}$ et al. (2007) revelam que o turno intermediário, correspondente ao horário das $11 \mathrm{~h}$ às $15 \mathrm{~h}$, e por isso chamado popularmente de turno da fome, tornou-se muito comum nas regiões de baixo nível sócio-econômico e alta concentração populacional.

\section{As dificuldades da escola determinadas pelo poder público}

Partindo das concepções anteriores, buscou-se identificar as principais dificuldades, ou pontos negativos, presentes na escola pública de ensino fundamental, que a levavam a descumprir o seu papel. Utilizou-se para tal a questão "Quais dificuldades você tem encontrado na escola pública?"

Para alguns desses docentes o assistencialismo era um problema, pois ocupava o horário destinado às aulas, o que comprometia também o cumprimento do currículo escolar planejado. Outra observação dizia respeito ao caráter da cidadania e da consciência política das futuras gerações, concebidas em meio a essas circunstâncias paternalistas do ensino público. Além disso, havia o despropósito dessas ações assistencialistas, em especial na Prefeitura de São Paulo, pois parte delas não atendia às verdadeiras necessidades de cada comunidade escolar. Tudo isso caracterizava o mau uso do dinheiro público destinado à educação, conforme afirma o discurso a seguir: "se a gente pegar os vários projetos da Prefeitura, a maioria realmente precisa do leite. Agora, o material escolar não chega a $10 \%$ dos alunos que estão usando, tirando o lápis e a caneta que é normal eles usarem. Então, gasta-se muito dinheiro com um monte de coisa que não precisa."

Outro aspecto relativo ao poder público que dificultava a escola de cumprir sua função referia-se à inexistência de um canal de comunicação democrático entre os gestores públicos e o professor, não havia espaço, portanto, para sua participação nas decisões e iniciativas voltadas à educação, conforme demonstrado nos depoimentos a seguir: "as pessoas que estão tratando da educação, em primeiro lugar não nos ouvem. Ninguém vem aqui para falar assim: Está funcionando? Como vocês estão trabalhando? Algum dia eles perguntaram na escola se esse programa novo que eles vão implantar, se isso funciona? Quem sabe o que é uma escola pública é quem está dentro dela."

De acordo com Zagury ${ }^{14}$ (2006), para superar a ineficiência dos projetos voltados à educação, evitando o desperdício de tempo e de recursos financeiros, é necessário e urgente que se dê voz aos professores, sistematicamente e em escala representativa, antes da implementação de novos projetos.

Outros docentes consideravam que o descaso dos gestores públicos com o professor, devido em parte ao despreparo administrativo junto às unidades escolares, como também ao desrespeito histórico do Estado em relação ao ensino básico, poderia ser entendido como um sinal da falta de prioridade despendida à educação pública, o que acentuava ainda mais a crise no sistema público de ensino e conduzia o docente a um exercício profissional de má qualidade. $\mathrm{O}$ discurso a seguir ilustra esse cenário: "com relação à saúde dos professores, o Secretário de Educação da gestão atual teve uma fala que não me agrada em nada, que o problema de saúde dos educadores acaba por decreto. Eu fiquei irritada, quando uma pessoa não está bem, ela não vem trabalhar, ela pode não pegar licença, mas ela abona, justifica, o normal é ela querer vir trabalhar, ter vontade de trabalhar."

Evidentemente, caso haja uma epidemia de desinteresse por parte considerável do professorado público, os gestores públicos perceberão, então, que não é por meio de leis, decretos ou portarias que esta questão será remediada ou solucionada. Além disso, conforme declarado no depoimento anterior, a falta de disposição de al- 
guns docentes pode significar um problema de saúde e deve ser tratado como tal.

Outra concepção encontrada nas entrevistas referia-se ao despreparo do Estado para atuar intersetorialmente - envolvendo áreas como a Educação, Saúde e Meio Ambiente - e à vulnerabilidade da rede pública de ensino diante das constantes mudanças de gestores. Desta forma, as iniciativas desenvolvidas, que definitivamente não consistem em políticas públicas, mas sim em políticas de governo ${ }^{++}$, dependiam, para sua continuidade, da boa vontade de políticos que na maioria das vezes estavam interessados apenas em sua autopromoção.

Para outros docentes, o desinteresse do poder público em promover uma educação de qualidade era o principal fator que levava a escola pública a descumprir o seu papel. Acreditavam que os gestores públicos estavam interessados em fazer da escola um palanque político, conforme delatado no seguinte discurso: "na escola pública as coisas não andam melhor, por uma questão política mesmo. A política então, só lembra da parte social, da parte educacional, da parte da saúde, só na época da eleição. Ninguém lá em cima está preocupado com o aproveitamento deles [alunos]."

Para alguns docentes, a rede pública de ensino era política e pedagogicamente refém das mudanças de gestão pública em todas as esferas. Para eles, não havia políticas públicas educacionais, e sim políticas partidárias, de curto prazo, ou seja, políticas de governo.

Constatou-se, também, que os métodos pedagógicos eram inadequados para atender às atuais demandas da sociedade, já que não eram contextualizados à realidade de cada comunidade e desconsideravam a heterogeneidade dos alunos da escola pública. Assim, para haver uma compreensão verdadeira das questões que inviabilizam parte das iniciativas educacionais, torna-se necessária uma análise crítica da realidade escolar. De acordo com Paro ${ }^{6}$ (2001, p. 131), "a escola pública tem baixa qualidade, antes de tudo e principalmente, porque, em seus métodos e conteúdos, não favorece a atualização histórico-cultural da criança e do adolescente de modo a se construírem como sujeitos históricos e em condições de exercitarem uma cidadania efetiva."

Para outros professores, a superlotação das salas de aula da escola pública de ensino fundamental - uma das principais diferenças em relação à escola particular - agravava consideravelmente a má qualidade do ensino, contribuindo para o descumprimento da sua função. Mesmo havendo uma legislação que determina o limite máximo de alunos por sala de aula, na prática, não é isso que acontece, conforme evidenciado no seguinte discurso: "não há condição, fica muito difícil. Porque as nossas salas são assim com 42, 45 alunos e chega mais um vão botando, se você deixar eles vão até 50, 60."

\section{Os reflexos do poder público na situação do professor}

Neste eixo da investigação, buscou-se compreender a verdadeira situação do professor em meio a esse cenário de profundas dificuldades e evidência de que a escola pública descumpria o seu papel. Utilizou-se para esse fim a pergunta, "Como você se sente nesse contexto da escola pública?".

Observou-se que a maior parte dos professores sentia-se: impotente; frustrado; desamparado; acomodado; desvalorizado; inculpado pela sociedade; e desinteressado pela rede pública de ensino.

Relacionado ao poder público, alguns desses docentes acreditavam estar falhando na sua função. Sentiam-se impotentes e desgastados devido ao assistencialismo arraigado, à não-retenção do aluno - fruto da política de progressão continuada -, ao desinteresse do poder público

Para Philippi et al. ${ }^{15}$ (2004, p. 691), políticas públicas "são um conjunto de diretrizes estabelecidas pela sociedade, por meio de sua representação política, em forma de lei." Políticas de governo "são aquelas que trazem propostas implementadas pelo Governo e estão diretamente vinculadas à administração que está exercendo o poder e que as têm como prioridade de ação durante o seu mandato." 
por uma educação de qualidade e, conforme discurso a seguir, à freqüente descontinuidade das iniciativas educacionais: "eu acho que o pior de tudo é essa coisa da descontinuidade e do professor receber um pacote, jogam um monte de coisa na mão da gente para gente ler e a gente lê aquilo e faz. Daqui a um ano já não é mais aquilo."

Outra concepção negativa, encontrada em parte dos depoimentos, relacionava-se ao sentimento de total desamparo dos professores em relação ao seu aperfeiçoamento profissional, sendo que, neste aspecto, a rede pública de ensino estadual era ainda pior que a municipal. Eles afirmavam ainda não contar com respaldo pedagógico e nem mesmo com a troca de experiências com outros professores, em especial na rede estadual.

Sentiam-se também desamparados em relação à sua qualidade de vida e à sua saúde física e psíquica. Torna-se evidente a urgência de se incluir nas políticas públicas educacionais o cuidado com a saúde dos professores, uma vez que esse descuido consiste em um fator determinante da atual má qualidade da educação pública.

Outro aspecto identificado pela pesquisa, e que teria surgido como consequiência da própria desvalorização social e econômica do professor da rede pública de ensino, foi a culpa atribuída a este profissional pelo fracasso da educação, conforme explicitado no seguinte discurso: "se a educação vai mal, o culpado é o professor, não se culpa a situação social, política, quem está administrando, se culpa o professor."

É preciso desvelar os verdadeiros determinantes desse fracasso do ensino público, considerando que a compreensão destes encontrase no interior da escola, junto a cada um dos atores da comunidade escolar. Caso contrário, torna-se difícil contrapor esses fatores às injustiças muitas vezes propositais, ou de incompetência técnica, por boa parte dos gestores públicos. Assim, não é justo responsabilizar apenas um único elo dessa estrutura sócio-educacional, no caso, o docente. Todos os atores da sociedade devem assumir sua parcela de responsabilidade e agir, o quanto antes, em busca de um novo paradigma educacional.

\section{O poder público e as iniciativas educacionais na saúde e no meio ambiente}

Considerando que a qualidade do meio ambiente consiste em um importante determinante da qualidade da saúde, e, portanto, não se pode abordar questões relacionadas à saúde sem considerar a complexidade dos aspectos intrínsecos à questão ambiental, buscou-se compreender como seria para o professor trabalhar com saúde e meio ambiente no ensino público fundamental e como o poder público abordava essas questões. Utilizou-se inicialmente, para o tema meio ambiente, o seguinte questionamento: “Tem gente que acha que a escola deveria trabalhar questões ligadas ao meio ambiente ${ }^{\S}$. $O$ que você acha disso? Na sua opinião, como deveriam ser abordadas essas ações?".

Constatou-se que todos os professores acreditavam na importância de se trabalhar o tema meio ambiente no ensino fundamental: contextualizando o tema localmente; sensibilizando o aluno e a comunidade; dando o exemplo; oferecendo uma formação adequada ao professor; e incluindo o tema no currículo escolar.

Em relação a essa última concepção e relacionado ao poder público, constatou-se que somente iniciativas pontuais não bastariam. $\mathrm{O}$ tema deveria ser incorporado ao currículo escolar e trabalhado em todas as séries da educação básica, sendo necessária, para tal, a devida preparação do professor.

Alguns docentes declararam que a escola pública de ensino fundamental já vinha trabalhando com a temática ambiental, porém sem sucesso. A questão era tratada superficialmente, e não havia apoio humano e estrutural do poder público. O discurso a seguir evidencia esses fatos: "um pouco as escolas trabalham, só que é muito superficial. Ás vezes a gente fala: 'ahh, vamos separar o lixo!' Mas e daí, quem vem

Para o tema saúde, foi utilizado a mesma questão trocando o termo meio ambiente por saúde. 
buscar? Então está faltando infra-estrutura do poder público." É claro que além de uma adequada infra-estrutura de apoio à rede pública de ensino no tratamento das questões sócio-ambientais, é visível a falta de vontade política dos gestores públicos para uma abordagem eficiente sobre o tema.

Por fim, alguns depoimentos indicaram que a escola pública abordava a temática ambiental por meio de pequenos projetos, voltados geralmente ao ciclo II do ensino fundamental - da $5^{\text {a }}$ a $8^{\mathrm{a}}$ série -, e que seria preciso ter mais apoio executivo e estrutural dos propositores. Assim, de acordo com o discurso, "vêm as propostas e tudo é bonito, mas você não tem ajuda de quem propôs. $O$ poder público sabe dessas nossas dificuldades."

Para o tema saúde, na opinião de alguns professores, a escola pública não deveria trabalhar questões ligadas à saúde, pois era preciso manter o seu foco unicamente na função educacional, evitando também sobrecarregar o docente. Caberia ao poder público oferecer um serviço de qualidade nesse setor. À escola caberia efetuar os encaminhamentos necessários aos postos de saúde e hospitais.

Percebe-se que a atenção à saúde ainda hoje é confundida com ações preventivas e informativas, sendo esse equívoco o motivo pelo qual muitos professores se negam a abordar essa questão, refletindo, também, nas iniciativas desenvolvidas pelas áreas da educação e da própria saúde. Saúde ainda é entendida como ausência de doença e não como qualidade de vida. Assim, é preciso que a escola, dentro de cada realidade e contexto, seja um ambiente promotor da saúde junto à comunidade na qual está inserida.

Porém, a maior parte dos professores acreditava que a escola pública deveria ser mais pró-ativa, atuando sempre dentro das necessidades e demandas da comunidade local, principalmente no que diz respeito às unidades escolares localizadas em regiões com perfil sócio-econômico mais baixo. Assim, para esses docentes, o tema saúde deveria fazer parte da abordagem da escola, por ser um espaço de formação de valores e hábitos, pelo vínculo estabelecido com a comunidade e também por trabalhar com a fatia da população mais necessitada. De acordo com o discurso a seguir, "a escola é a instituição que tem mais chances de trazer mais pais, mães, então eu acho que a escola deve tratar sim [da saúde]. É muito importante, eles vivenciam um mundo muito perverso, e trazem tudo isso para sala de aula. Então é super necessário, faz parte da educação também."

Desta forma, predominaram as concepções de que a escola fundamental deveria sim trabalhar a saúde: informando; prevenindo; sensibilizando o aluno; relacionando o tema com o meio ambiente; estabelecendo parcerias; como conteúdo curricular; por meio de projetos; com especialistas na escola; aprimorando as ações junto aos postos de saúde; deveria, mas não dá conta de mais essa função; e utilizando método pedagógico adequado.

Para alguns professores, a rede pública de ensino fundamental deveria atuar efetivamente com as questões ligadas à saúde, de forma que envolvesse toda a escola, e não ficasse somente sob uma perspectiva superficial, sazonal e disciplinar.

Outros professores acreditavam que o tema saúde, por estar intimamente ligado à educação, deveria ser obrigatório no currículo escolar de toda a rede pública de ensino fundamental, disciplinar ou transversalmente, além de estar presente no material didático. Outra possibilidade de se desenvolver um trabalho com a saúde, segundo os professores, seria por meio de projetos contextualizados e participativos, desenvolvidos em conjunto com gestores públicos, educadores da escola e com a comunidade, concebidos a partir de cada realidade local e conforme a disponibilidade desses atores.

Alguns professores defendiam a idéia de se ter especialistas da saúde dentro da escola, já que eles, docentes, não tinham o preparo necessário para cumprir essa função. Esses profissionais da saúde os orientariam, assim como orientariam e atenderiam os alunos em suas necessidades, conforme revelado no discurso a seguir: "profissionais da área atuando dentro da escola, avaliação psicológica, da parte emocional, mental, o que eu entendo disso? A gen- 
te age com o bom senso, com o coração."

Para outros, no entanto, não deveria haver especialistas atuando dentro da escola pública. Seria preciso, sim, aprimorar o serviço público de saúde disponível à sociedade, especialmente aos educandos, buscando maior integração com os postos de saúde e hospitais, desenvolvendo, assim, uma parceria mais eficiente, que implicasse não só a qualidade do atendimento, mas também a troca de informações, a orientação e a sensibilização tanto dos professores quanto dos alunos e da comunidade local.

Alguns docentes ainda consideravam que as questões relacionadas à saúde do aluno eram dos maiores problemas da escola pública de ensino fundamental e, assim, eram a favor de que se trabalhasse a questão na instituição. No entanto, acreditavam que a escola não daria conta de atender a mais essa demanda, o que fatalmente concorreria com a sua função educativa, sobrecarregando-a.

Outros professores, independente do poder público e embora ainda superficiais e sem continuidade, a escola já desenvolvia algumas iniciativas de prevenção em saúde - higiene pessoal, saúde bucal e alimentação -, inseridas na disciplina de Ciências. De acordo com Pelicioni ${ }^{16}$ (2000), a maior parte das ações em saúde na escola estão, ainda, centradas na tentativa de mudar comportamentos, desconsiderando as inúmeras influências, provenientes da realidade e contexto, nos quais o aluno está inserido. Assim, é preciso considerar a variedade de fatores que podem afetar a saúde e, consequientemente, a qualidade de vida das gerações atuais e futuras.

Identificadas as representações dos professores sobre a inclusão das temáticas saúde e meio ambiente no plano de trabalho da rede pública de ensino fundamental, buscou-se entender como o poder público estava abordando essa questão. Para este fim, utilizou-se o seguinte questionamento: “Os gestores públicos têm trazido alguma proposta para trabalhar questões ligadas à saúde ${ }^{\S \S}$ nas escolas? Quais? O que você achou disso?".

A idéia de que o poder público tem apre- sentado propostas em saúde escolar foi identificada junto a praticamente a metade dos professores entrevistados, sendo que estas ocorriam: em saúde ocular; por meio de material informativo; por meio de levantamentos sobre a saúde do aluno; e por meio de cursos para o professor.

Assim, para alguns docentes, o programa anual de acuidade visual, da rede de ensino municipal de São Paulo, era a única iniciativa percebida na área de saúde. Acreditavam que a escola não tinha infra-estrutura adequada para promover ações com qualidade na área de saúde, como ficou evidenciado no discurso a seguir: "é tão precário o teste que nós fizemos, porque não tem lugar na escola, é dentro da sala de aula, eu finjo que estou dando, e quem garante que esse exame é confiável, com a confusão de uma sala de 40 alunos."

Fica evidente a falta de confiabilidade desse programa, que poderia, por um eventual erro de diagnóstico que implicasse no não-encaminhamento do aluno, comprometer todo o seu aprendizado futuro. Percebe-se aqui, mais uma vez, o alto risco de fracasso das iniciativas que ocorrem junto à escola pública quando estas não envolvem os educadores na sua concepção, planejamento e implantação. A existência dessa percepção nos professores reduz, consideravelmente, as possibilidades de inovação no ensino público, pois, os docentes não se sentem motivados a cooperar com aquilo que esteja além da sua obrigação formal.

Os professores consideravam, também, que as iniciativas do poder público em saúde eram apenas políticas de uma determinada gestão e, por isso, não havia continuidade. Para outros, as ações na rede pública municipal de ensino fundamental eram muito poucas, porém, ainda assim, eram mais constantes que na rede estadual, e contavam com apostilas ou informativos temáticos, que geralmente eram entregues ao professor de Ciências. Acreditavam ser um erro de estratégia a utilização desse tipo de material na escola, pois esses não atendiam às verdadeiras necessidades e especificidades locais; além disso, essas ações, geralmente, por serem vincula-

$\S \S$ Para o tema meio ambiente, utilizou-se a mesma questão trocando o termo saúde por meio ambiente. 
das às campanhas sazonais dos gestores públicos, não sensibilizavam o educando e a comunidade local.

Para outros docentes, os gestores públicos ofereciam apenas cursos na área de saúde, como era o caso da capacitação para inclusão de deficientes visuais na escola. Porém esses cursos, segundo eles, tornavam-se inviáveis, devido aos horários em que eram oferecidos, concorrendo com o período letivo e com a sua pesada carga horária.

Assim, na opinião desse grupo de docentes, embora houvesse iniciativas referentes à saúde na rede pública de ensino fundamental, essas se davam de forma superficial, descontínua, eram voltadas, geralmente, aos interesses políticos do poder público e praticamente não aconteciam ou não eram percebidas nas escolas da rede pública estadual.

A outra parte dos professores entendia que não havia, ou que pelo menos lhes era desconhecido, qualquer tipo de iniciativa na área de saúde por parte do poder público, tanto na rede municipal quanto na rede estadual de ensino da cidade de São Paulo. Acreditavam que as ações voltadas à saúde, por não promoverem visibilidade política, ficavam apenas nas promessas do governo, como foi o caso do programa Escola Promotora de Saúde, da atual gestão municipal. Consideravam ainda que a falta de políticas públicas específicas na área da saúde consistia a principal razão dos altos índices de evasão escolar daqueles alunos que apresentavam algum tipo de problema de saúde.

Nos resultados do Censo Escolar Brasileiro de 2006 referente ao ano de 2005, a taxa de abandono no ensino fundamental do estado de São Paulo era, $2,7 \%$ na rede estadual de ensino, $1,0 \%$ na rede municipal de ensino e $0,2 \%$ na rede particular de ensino (INEP 3 , 2007), revelando um cenário assustador no ensino público fundamental, tanto em números absolutos, 70 mil alunos, quanto em comparação com a educação particular.

Fica evidente que o exercício desinteressado dos gestores públicos e a falta de prioridade dada às políticas públicas educacionais eficientes são condicionantes que acarretam uma série de obstáculos ao aprendizado do aluno, e, conseqüentemente, leva a escola pública de ensino fundamental a descumprir o seu papel.

Relacionado ao tema meio ambiente, verificou-se que, para boa parte dos docentes, o poder público apresentava à escola iniciativas pontuais que, além de inconsistentes, também não tinham o caráter de obrigatoriedade. Essas propostas eram geralmente resultantes de parcerias estabelecidas com o setor privado e contemplavam um número insignificante de escolas. Além disso, não tinham continuidade e não estavam integradas a outros campos de conhecimento. Observou-se, também, que geralmente os gestores públicos não eram pró-ativos, cabendo ao setor privado buscar as parcerias.

Devido às constantes mudanças de gestão, é preciso chamar a atenção para a vulnerabilidade das iniciativas trazidas pelo poder público, o que evidencia o seu desinteresse pela educação pública e também o seu despreparo para atuar intersetorialmente em áreas como o meio ambiente, bem como a saúde, conforme já abordado anteriormente.

Já a outra parte desses docentes afirmava que não havia, por parte do poder público, nenhuma iniciativa relativa ao meio ambiente na rede pública de ensino, principalmente na estadual, sendo que as propostas ficavam apenas no plano teórico. Eles acreditavam que isso se devia, em boa parte, ao desinteresse da própria sociedade pelo assunto, o que levava conseqüentemente ao desinteresse político do poder público, conforme verificado no discurso a seguir: " $u m$ poder público que prefere mandar a verba para outras coisas que dão mais bandeira do que fazer esses pequenos trabalhos que trouxessem mais qualidade de vida."

Seguindo as concepções encontradas junto ao tema saúde, constatou-se que as iniciativas existentes na rede pública de ensino, relacionadas ao meio ambiente, eram concebidas por meio de parcerias estabelecidas pela direção da própria escola com o setor privado e o terceiro setor.

\section{CONCLUINDO?}

Todos esses aspectos evidenciam a atual 
crise da educação pública básica, uma síntese do despreparo administrativo e do desrespeito histórico do poder público, em especial com a escola pública fundamental, o que afeta diretamente o desenvolvimento político, cidadão, ético e intelectual de grande parte da população brasileira, dependente dessa instituição e que por sua vez depende diretamente da qualidade do trabalho do professor.

É notório que para compreender a situação da escola pública, é importante dar voz aos professores, conforme constatado nos seus depoimentos. Fica evidente também que não há, efetivamente, na estrutura burocrática do setor educacional, o envolvimento desses docentes na construção de políticas públicas educacionais, que são geralmente calcadas no histórico autoritarismo do poder público.

Desta forma, o professor não participa das tomadas de decisão, atuando na prática, como um mero executor. Essa postura imperativa dos gestores públicos não permitia nem mesmo a sensibilização desses profissionais diante das propostas apresentadas e, por isso, estas são parcialmente alcançadas ou fracassavam na sua totalidade.

Cabe ao poder público estabelecer um diálogo verdadeiro com o professor, buscando soluções a partir do amplo entendimento sobre a escola pública. Desta forma, seria possível a promoção de políticas públicas educacionais que fossem cúmplices da produção de um conhecimento libertador, reflexivo, crítico, político e transformador, o que somente se conseguirá a partir da melhor qualidade da prática de ensino-aprendizagem, em todos os níveis do sistema público de ensino básico. À sociedade cabe engajar-se, assumir sua responsabilidade e exigir o seu espaço de participação na educação pública, pois sabe-se que essa é a principal forma de controle das atividades pedagógicas e da aplicação de recursos educacionais dentro de cada necessidade e realidade.

\begin{abstract}
Brazilian society does not have high-quality public education because it is not a priority of the public power. On the other hand, the State does not prioritize education because it has not been a demand of society. To legitimate any debate on education, it is necessary to involve the real protagonists, the teachers. A qualitative research was conducted with teachers from a municipal elementary school in São Paulo, Brazil. The aim was to identify, through semistructured interviews, their social representations on the present role of the public school and the public power's initiatives that have been trying to integrate areas like health and environment into the school these days. On the topic analyzed here, "public power and public school", it has been found that paternalism, inefficacy of public policies and governors' lack of knowledge on school practices are evidences of the State's lack of interest in the development of quality schools, which ends up determining that the school is not able to play its social role. The teacher has been feeling more and more impotent, unvalued and uninterested in public education. Therefore, it is now time for society to undertake its responsibility towards public education. The public power, in turn, must not only know, but also experience the school, establishing a true dialog with the teacher. Through education, it must search for a sustainable social transformation based on new human values concerning ethics and justice.
\end{abstract}

Keywords: Elementary education, Quality education, Health promotion, Teacher, Public power, Qualitative research.

\section{REFERENCIAS}

1. Squizato R. Educação: lições por fazer. Rev Página 22. 2006;2:20-31.

2. Freire P. Pedagogia da autonomia: saberes necessários à prática educativa. 27. ed. São Paulo: Paz e Terra; 1996.
3. INEP - Instituto Nacional de Estudos e Pesquisas Educacionais Anísio Teixeira. Censo escolar da educação básica 2006 [base de dados na Internet]. [acesso em 06 de jul 2007] Disponível em: http://www.inep.gov.br/basica/ censo/Escolar/resultados.htm.

4. OECD - Organization for Economic Co- 
operation and Development. Education at a glance: OECD Indicators. Paris; 2006.

5. Cunha C. Fundeb falha ao não definir metas, afirma especialista. Folha de São Paulo, 2006 dez 11; Caderno Cotidiano:4.

6. Paro VH. Políticas educacionais: considerações sobre o discurso genérico e a abstração da realidade. In: Paro VH. Escritos sobre educação. São Paulo: Xamã; 2001. p. 121-39.

7. Minayo MCS. Ciência, técnica e arte: o desafio da pesquisa social. In: Deslandes SF, Cruz Neto O, Gomes R, Minayo MCS, organizadores. Pesquisa Social: Teoria, Método e Criatividade. 24. ed. Petrópolis: Vozes; 1994. p. 9-30.

8. Lefèvre F, Lefèvre AMC, Teixeira JJV. O discurso do sujeito coletivo: uma nova abordagem metodológica em pesquisa qualitativa. Caxias do Sul: EDUCS; 2000.

9. Moscovici S. A representação social da psicanálise. Rio de Janeiro: Zahar; 1978.

10. Michelat G. Sobre a utilização da entrevista nãodiretiva em sociologia. In: Thiollent MJM. Crítica metodológica, investigação social e enquete operária. 5. ed. São Paulo: Polis, 1987. p. 191-211.

11. Bardin L. Análise de conteúdo. 70. ed. Lisboa; 1979.

12. Lefèvre F, Lefèvre AMC. O discurso do sujeito coletivo: um novo enfoque em pesquisa qualitativa (desdobramentos). Caxias do Sul: EDUCS; 2005.

13. Góis A, Takahashi F. Escolas próximas têm médias distantes. Folha de S. Paulo, 2007 mar 31; Caderno Cotidiano:5.

14. Zagury T. O professor refém: para pais e professores entenderem por que fracassa a educação no Brasil. Rio de Janeiro: Record; 2006.

15. Philippi Jr A, Bruna GC. Política e gestão ambiental. In: Philippi Jr A, Romero MA, Bruna GC, editores. Curso de gestão ambiental. Barueri: Manole; 2004. p. 657-711. (Coleção Ambiental,1).

16. Pelicioni MCF. Educação em saúde e educação ambiental: estratégias de construção da escola promotora da saúde. [tese de livre-docência]. São Paulo: Faculdade de Saúde Pública da USP; 2000 . 